\title{
EDITORIAL
}

\section{Mujeres y ciencia: a propósito del Premio Nobel}

\author{
Carla Macchia-de Sánchez (iD) ${ }^{1}$, Vivian Villalba-Vizcaíno (iD ${ }^{2}$
}

1. Universidad del Magdalena. Santa Marta, Colombia. Correo: cmacchia@unimagdalena.edu.co - https://orcid.org/0000-0003-2822-2943
2. Universidad del Magdalena. Santa Marta, Colombia. Correo: vvillalba@unimagdalena.edu.co - https://orcid.org/0000-0002-0281-2796

El mundo científico siempre se ha mostrado como un terreno competitivo donde el éxito es directamente proporcional a la dedicación de tiempo y el género, siendo los hombres quienes histórica y socialmente cumplen estos requisitos. Por lo anterior, las mujeres han tenido poca visibilidad. Sin embargo, a lo largo de la historia se han logrado sortear los obstáculos que supone la dedicación de tiempo y las limitaciones que clásicamente se asocian al género, buscando cumplir con los deseos de hacer ciencia. A pesar de estos esfuerzos y de lograr algunos reconocimientos como los premios nobel de Marie Curie y la incursión en varios campos del conocimiento, algunas mujeres permanecen desdibujadas y ocultas a pesar de los importantes aportes realizados a la ciencia y sólo gracias a algunas películas y documentales se dan a conocer, generando sorpresas y cumpliéndose en ocasiones la premisa: "Detrás de cada hombre hay una gran mujer".

Es llamativo observar que son escasas las mujeres que han conseguido acceder a los más altos reconocimientos en el campo del saber; tal vez porque tradicionalmente han existido, y en ciertas sociedades aún hoy se perpetúan, patrones culturales de subordinación y otras conductas conocidas en conjunto como "techos de cristal", que constituyen barreras que impiden el posicionamiento y la visibilidad de las mujeres dedicadas a las ciencias e incluso otros campos. Uno de los ejemplos de mujeres brillantes de la ciencia que están dentro de ese grupo desconocido y también oculto es Hipatia de Alejandría que terminó acusada de herejía, así como tantos personajes femeninos que fueron asociados más con la brujería 0 artes oscuras ${ }^{1}$.

El devenir del tiempo va transcurriendo desde construcciones simbólicas y discursos legitimantes de la desigualdad, avalando estereotipos de mujerama de casa, incompatible con una persona de ciencia, hasta el logro de conquistas como la obtención paulatina de más cargos jerárquicos dentro de las estructuras organizativas tanto académicas como empresariales.

El colectivo de mujeres científicas consigue así progresivamente mayor visibilidad. En el país nace en 2016 la Red Colombiana de Mujeres Científicas, la cual nuclea investigadoras destacadas de diferentes regiones. Esta agrupación define su plan de trabajo con relación a cinco ejes estratégicos impregnados con una profunda visión de género: motivación de las niñas en las ciencias, tutoría de jóvenes científicas, políticas de género en ciencias en Colombia, Género, ambiente y salud, y el empoderamiento de las científicas ${ }^{2}$.

Al interior de los claustros universitarios también se van gestando transformaciones, y la labor de la mujer de ciencia paulatinamente va cobrando más peso. Más recientemente, la fuerte presencia femenina en la entrega de los Premios Nobel en Estocolmo no pasa inadvertida, si bien los hombres 
mayoritariamente habían resultado ganadores desde 1901 hasta la fecha. Hacia finales de 2017 el balance contabilizaba 599 distinciones otorgadas a varones y tan sólo dieciocho a mujeres. En el año 2018 dos científicas lograban este galardón: Donna Strickland (Nobel de Física), y Frances Arnold (Nobel de Química). El 2020 sorprende con tres investigadoras premiadas: El Nobel de Física, otorgado a la estadounidense Andrea Ghez, junto con el inglés Roger Penrose y el alemán Reinhard Genzel, por sus contribuciones a la investigación sobre agujeros negros, estructuras intrigantes en las cuales todo parece desaparecer, inclusive, las leyes de la física. Por su parte, la Academia Sueca concede el Nobel de Química a Jennifer Doudna, bioquímica estadounidense, y a la microbióloga y bioquímica francesa Emmanuelle Charpentier, laureando sus aportes en edición del genoma, con las llamadas "tijeras genéticas CRISPR/Cas9"3,4.

Durante el 2020 la situación epidemiológica mundial demandó de las mujeres mucho más esfuerzo y compromiso, particularmente para las trabajadoras del área de la salud, quienes debieron balancear las exigencias propias de su ejercicio académicoprofesional con las tareas de cuidado en el hogar. Por esto la necesidad del llamado a brindar el apoyo y espacio desde el sitio más importante de desarrollo para una mujer, su familia (sea cualquiera su conformación) ya que desde aquí libramos nuestras más grandes batallas por lograr el equilibrio y alcanzar nuestros sueños. En este mundo de nuevas oportunidades, aún experimentamos situaciones de discriminación y maltrato, así como menor acceso a herramientas para desarrollar nuestras actividades científicas, por lo que seguimos luchando en lo que parece seguir siendo un mundo exclusivo de hombres. Pero en medio de todo este panorama, por desalentador que parezca, hay luces de esperanza en quienes todavía creemos en la equidad y en el poder femenino para alcanzar las metas propuestas.

El Grupo de Investigación en Inmunología y Patología (GIPAT) de la Universidad del Magdalena se une a la celebración, y hace extensivo el reconocimiento a toda la comunidad de científicas e investigadoras que día a día prosiguen con sus sueños a pesar de las dificultades.

\section{Nota}

El Grupo GIPAT de la Universidad del Magdalena, se encuentra conformado mayoritariamente por mujeres destacadas en cada una de sus especialidades, cuyo propósito es unir esfuerzos para comprender algunas patologías importantes en nuestro medio, integrando sus saberes desde la Inmunología, Pediatría, Patología, Bacteriología, Endocrinología Reproductiva. Este grupo desde sus inicios ha impulsado las ideas de sus integrantes quienes con esfuerzo y dedicación han logrado posicionarlo como categoría $B$ dentro del Sistema de CTel del Ministerio de Ciencia y Tecnología, con lo que tributan nuevo conocimiento a los estudiantes del Programa de Medicina de la Universidad del Magdalena.

\section{DECLARACIÓN SOBRE CONFLICTOS DE INTERES}

Ninguno que declarar.

\section{REFERENCIAS BIBLIOGRÁFICAS}

1. Guil Bozal A. Mujeres y ciencia: techos de cristal. EccoS Revista Científica 2008; 10 (1): 213- 232. Doi: https://doi.org/10.5585/eccos.v10i1.1056

2. Red Colombiana de Mujeres Científicas. Disponible en:

https://www.redcolombianamujerescientificas.org/

3. Página oficial del Premio Nobel (Categoría: Física). Disponible en: https://www.nobelprize.org/prizes/physics/

4. Página oficial del Premio Nobel (Categoría: Química). Disponible https://www.nobelprize.org/prizes/chemistry/ 